\title{
Effects of Risk Perception on Disaster Preparedness Toward Typhoons: An Application of the Extended Theory of Planned Behavior
}

\author{
Sai Leung $\mathbf{N g}^{1}$
}

Accepted: 2 February 2022/Published online: 15 February 2022

(C) The Author(s) 2022

\begin{abstract}
This study adopted an extended theory of planned behavior to understand how risk perception affected disaster preparedness behavior. An intercept survey $(\mathrm{N}=$ 286) was conducted at a typhoon-prone district of Hong Kong, China in 2019, then the data were analyzed using structural equation modeling. The results indicated that risk perception and intention of preparedness were predictors of disaster preparedness behavior. Risk perception significantly affected intention of preparedness and the effect was partially mediated by subjective norm. Risk perception also significantly affected attitude and perceived behavioral control, but attitude and perceived behavioral control were not significantly correlated with intention of preparedness. Not only may this study supplement the existing literature of disaster preparedness toward typhoons, but also it provides insights for the planning and management of natural hazards and disaster risk reduction in Hong Kong.
\end{abstract}

Keywords Disaster preparedness behaviour · Hong

Kong · Risk perception - Structural equation modelling - Theory of planned behaviour - Typhoon preparedness

\section{Introduction}

Tropical cyclones, also known as typhoons in Asia or hurricanes in North America, refer to intense low-pressure systems observed in tropical and subtropical oceans.

Sai Leung $\mathrm{Ng}$

ws17@ulive.pccu.edu.tw

1 Graduate Institute of Earth Science, Chinese Culture University, Taipei 11114, Taiwan, China
Tropical cyclones bring strong winds and torrential rains that may directly result in physical destruction, they may further cause flooding, landslides, and storm surge that lead to sequential impacts on the affected areas. Globally, tropical cyclones are responsible for the largest proportion of mortality and economic loss among various meteorological hazards (Fok and Cheung 2012), although a decreasing trend of mortality was observed in the past 70 years (Doocy et al. 2013).

Typhoons are the most common natural hazard in subtropical East Asia (Fok and Cheung 2012). On average, Hong Kong is affected by approximately five typhoons every year (Hong Kong Observatory 2020). In Hong Kong, typhoons have caused the most casualties and damages among various natural hazards (Johnson et al. 2016). From 1980 to 2010, on average, the annual mortality and economic damage are 2.6 people and USD 8.1 million, respectively (Fok and Cheung 2012).

Hong Kong, like many coastal cities in China and around the world, is predicted to be at risk of climate change (Sundermann et al. 2013). Specifically, global warming is expected to increase the frequency and intensity of typhoons in the West Pacific (Webster et al. 2005), and Hong Kong has already experienced an increasing trend of extreme typhoons brought by global warming. In the past 40 years, only two signal no. 10 typhoons $^{1}$ occurred from 1980 to 2010 . However, there were three signal no. 10 typhoons in the last decade (that is, 2012, 2017, and 2018).

Facing the challenges of typhoons, a considerable number of studies have examined their physical attributes,

\footnotetext{
1 A warning signal is hoisted if a tropical cyclone approaches within a distance of $800 \mathrm{~km}$ to Hong Kong. Signal no. 10 represents the highest level of typhoon intensity.
} 
including number, duration, and intensity (Webster et al. 2005; Lam and To 2009). These studies help predict the future occurrence of typhoons in Hong Kong so that possible mitigation plans and measures can be formulated. However, the need for proactive strategies and measures of risk reduction aiming to reduce hazard vulnerability in the process of disaster management is equally important (UNISDR 2015; Paton 2019).

Disaster preparedness refers to activities and measures taken in advance to ensure an effective response to the impact of hazards (Paton 2019; Dasgupta et al. 2020). Preparedness increases people's capacity to cope, adapt, respond, and recover when disaster strikes. Consequently, the costs of natural hazard-related disasters can be reduced (Paton 2019). Yet, disaster preparedness is one of the weakest links in the risk management system of Hong Kong. One local study indicated that $69 \%$ of residents took no precautions even when they were aware of a severe weather warning (Wong and Yan 2002). Another local study indicated that only $22.4 \%$ of the respondents were prepared for natural hazard-related disasters (Loke et al. 2010).

Although these studies are valuable in understanding the situation of personal preparedness toward typhoons in Hong Kong, our knowledge is limited to the description of the phenomena. To promote personal preparedness in society, it is necessary to understand the factors that motivate or inhibit disaster preparedness behavior (Najafi et al. 2017). However, the majority of previous studies of disaster preparedness behavior were lack of underpinned theory. Furthermore, vulnerable people deserve more attention as they may need extra assistance during disasters, but very few studies have been conducted to investigate them (Kuran et al. 2020).

With the above considerations in mind, this study adopted an extended theory of planned behavior (Ajzen 1991) to investigate the disaster preparedness behavior of typhoon-vulnerable people in Hong Kong, using first-hand data from an intercept survey conducted on the streets of Kwun Tong district from December 2018 to May 2019. Not only may this study supplement the body of knowledge on disaster preparedness toward typhoons, but also it provides a reference for the development of effective management of typhoon disasters in Hong Kong and other coastal cities in Asia.

\section{Literature Review}

The theory of planned behavior and risk perception have been used to explain goal-directed behaviors (Ajzen 2011) and disaster preparedness, respectively. To the best of my knowledge, there is no attempt to incorporate risk perception into the theory of planned behavior to understand an individual's disaster preparedness behavior toward typhoons. To lay the theoretical foundation, the key concepts and related studies are first summarized by reviewing the existing literature of behavioral sciences and hazard management. Along with the formulation of hypotheses, the integration of the theory of planned behavior and risk perception is elaborated.

\subsection{Disaster Preparedness Behavior and the Theory of Planned Behavior}

Disaster preparedness behavior refers to the personal undertaking of activities or measures before a hazard event in order to mitigate the severity of disaster impacts (Dasgupta et al. 2020). Although the connotations of disaster preparedness behavior are varied in time, place, and type of natural hazard (Fung and Loke 2010), two common components can be found in the majority of existing literature: preparing an emergency kit and making an emergency plan (Paul and Bhuiyan 2010; Kohn et al. 2012; Lam et al. 2017). The emergency kit usually refers to a package of items for survival, such as clean water, food, and first-aid supplies (Fung and Loke 2010). The emergency plan refers to specific procedures for handling sudden or unexpected situations (Bhanumurthy et al. 2015). Considering the urban context of Hong Kong, a simple first-aid kit is sufficient for typhoon preparedness (Chan et al. 2016). While formal emergency plans may not be necessary (Lam et al. 2017), the plan may refer to the consent of family members, for example, going out with an umbrella or simply canceling the trip according to the weather condition.

The performance of disaster preparedness behavior, like other environmental behaviors, is controlled by various factors, but the process is still not well understood (Najifi et al. 2017). Therefore, it is preferable to adopt a behavioral model to guide the research (Najafi et al. 2018). Many behavioral models have been developed to understand and predict human behavior. Among them, the theory of planned behavior is the most influential and widely used model (Ajzen 2011). The theory of planned behavior has two central propositions. First, an individual's intention is the immediate cause for the performance of a given behavior. Second, intention is determined by three preceding motivational factors, namely attitude, subjective norm, and perceived behavioral control (Ajzen 1991).

Intention refers to the voluntary decision to perform a particular behavior or take an action (Sheeran 2002). In a meta-analysis that included 422 studies of intention and behavior relations in various contexts, the mean correlation between intention and behavior was 0.53 (Sheeran 2002). Another meta-analysis including 206 independent studies reported a mean correlation of 0.43 (McEachan et al. 
2011). Because the predictive power of intention was usually higher than socio-demographic and other behavioral factors, many studies considered intention as a proxy measure of the actual behavior (for example, Jang et al. 2016).

In the theory of planned behavior, attitude is the first construct affecting intention. Attitude refers to the extent to which a person develops a positive or negative perception toward a given behavior (Ajzen 1991). Attitude may be categorized as cognitive (that is, beliefs or knowledge about an attitude object), affective (that is, the feelings or emotions toward an object), and behavioral (that is, the way that a person has influenced his or her behavior) (Eagly and Chaiken 2007). Significant associations between attitude and intention can be found in various settings and contexts, which is evident from a large number of published works.

The second construct is subjective norm, which reflects a person's perceptions of how others expect him or her to behave (Ajzen 1991). Subjective norm consists of injunctive (that is, how the social network wants this person to behave) and descriptive (that is, the behavior of the social network) components (Daellenbach et al. 2018).

The last construct, perceived behavioral control, is the volitional factor in the theory of planned behavior. It incorporates a person's perception of his or her capacity or control over the behavior (Ajzen 1991). Perceived behavioral control consists of internal (that is, self-efficacy; the belief for a person to be capable of performing a given behavior) and external (that is, perceived controllability; the barriers to performing a given behavior) components (Ajzen 2002). Manstead and van Eekelen (1998) indicated that self-efficacy mainly affected intention and perceived controllability influenced behavior, respectively. Therefore, perceived behavioral control affects both behavioral intention and actual behavior (Ajzen 1991, 2002).

In a meta-analysis that included 185 independent studies using the theory of planned behavior to predict human behaviors in various contexts, the mean correlation between intention and attitude was 0.49 , that of subjective norm was 0.34 , and that of perceived behavioral control was 0.43 , respectively (Armitage and Conner 2001).

In the context of hazard studies, the theory of planned behavior had been successfully used to explain the behavioral adjustments related to natural hazards (for example, earthquakes (Najafi et al. 2017), and typhoons (Dasgupta et al. 2020)), and threats of anthropogenic origins (for example, terrorist attacks (Tan et al. 2020)).

Based on the theory of planned behavior, this study formulated five hypotheses:
Hypothesis 1 Intention of typhoon preparedness positively affects disaster preparedness behavior toward typhoons.

Hypothesis 2 Attitude toward typhoon preparedness positively affects intention of typhoon preparedness.

Hypothesis 3 Subjective norm of typhoon preparedness positively affects intention of typhoon preparedness.

Hypothesis 4 Perceived behavioral control of typhoon preparedness positively affects intention of typhoon preparedness.

Hypothesis 5 Perceived behavioral control of typhoon preparedness positively affects disaster preparedness behavior toward typhoons.

\subsection{Risk Perception and Disaster Preparedness Behavior}

Despite the success of the theory of planned behavior, some researchers, for example, Sommestad et al. (2015), questioned whether the three variables in the model-attitude, subjective norm, and perceived behavioral controlwere sufficient to predict intention. As a response to the challenge, Ajzen (1991) indicated that the theory of planned behavior was open to the inclusion of additional variables, when they made significant and distinct contributions.

In the context of disaster preparedness behavior, risk perception is central to a large number of previous studies of disaster preparedness (Paul and Bhuiyan 2010; Shreve et al. 2016). The popularity of risk perception speaks for its potential to extend the theory of planned behavior for predicting disaster preparedness behavior. Existing literature indicated that humans adopted preparedness measures and behaviors only when they perceived that they were under the threat of a disaster (Lazo et al. 2015).

Risk perception refers to personal judgment about the uncertainty associated with the disaster (Paul and Bhuiyan 2010; Bourque et al. 2012). It is not the objective reality but a subjective evaluation of risk (Xu et al. 2016). Most researchers adopted a three-factor model of risk perception: (1) perceived likelihood (that is, the probability of a disaster to occur); (2) perceived severity (that is, the potential damage caused by the disaster); and (3) perceived susceptibility (that is the individual's constitutional vulnerability to a hazard) (Brewer et al. 2007; Shreve et al. 2016).

A meta-analysis of several empirical studies of risk perception reported significant associations between risk perception and risk-taking behavior; the overall weighted effect size was -0.70 (Cooper and Faseruk 2011). Another meta-analysis of 34 risk perception studies also reported significant correlations between risk perception and 
behavior; the correlation ranged from 0.16 to 0.26 (Brewer et al. 2007). Bourque et al. (2012) indicated that risk perception was a necessary predictor of preparedness, but it might not be a sufficient predictor.

Based on the findings in the literature, two hypotheses are formulated:

Hypothesis 6 Risk perception of typhoons positively affects disaster preparedness behavior.

Hypothesis 7 Risk perception of typhoons positively affects intention of typhoon preparedness.

\subsection{Risk Perception and the Theory of Planned Behavior}

Previous studies also reported relations between risk perception and a person's attitude, subjective norm, and perceived behavioral control of natural hazards, prompting the possibility that these variables mediated the effects of risk perception on disaster preparedness behavior.

First, relations between risk perception and attitude have long been identified by previous literature of natural hazards (for example, Marti et al. 2017). The Risk Perception Attitude framework describes the effects of risk perception on behaviors that form different attitude scenarios (Rimal and Real 2003). The Risk Perception Attitude framework recently was applied in risk management (for example, Liu-Lastres et al. 2019).

Second, both risk perception and subjective norm are socially and culturally shaped by society (Najafi et al. 2017). While risk perception provides values or meanings for the potential disaster (McIvor and Paton 2007), the internalization of these values forms subjective norms (Khalil et al. 2014).

Third, an association is believed to exist between risk perception and perceived behavioral control because both internal and external controls of behavior are related to people's perception of the context of the issue (Liu-Lastres et al. 2019).

Based on the findings in the literature, three hypotheses are formulated:

Hypothesis 8 Risk perception of typhoons positively affects attitude toward typhoon preparedness.

Hypothesis 9 Risk perception of typhoons positively affects subjective norm of typhoon preparedness.

Hypothesis 10 Risk perception of typhoons positively affects perceived behavioral control of typhoon preparedness.

Combining the above observations, this study proposed a conceptual framework that extended the theory of planned behavior by adding risk perception as a new variable for predicting disaster preparedness behavior of typhoon vulnerable people in Hong Kong (Fig. 1).

\section{Methods}

This study conducted an intercept survey at a typhoonprone district of Hong Kong. The survey period was from December 2018 to May 2019, before the start of a typhoon season, so that the respondents expressed general opinions toward typhoon preparedness without the interference of recent typhoon events.

\subsection{Questionnaire}

A structured questionnaire was developed according to the conceptual framework presented in Fig. 1. Excluding the question items to determine the socio-demographic characteristics of respondents, there were 17 items that belonged to six sections (Table 1). All instrument items were adopted from previous literature and modified to fit the current research context. Except for the question items of attitude, which used a 5-point bipolar semantic differential scale ranging from -2 to 2 , all questions were set with a Likert scale ranging from 1 (strongly disagree) to 5 (strongly agree). Two independent experts in the field were invited to review the questionnaire and a pilot survey was conducted for the revision of ambiguous or unclear wording.

The measurement items of attitude, subjective norm, perceived behavioral control, and intention of disaster preparedness were adapted from Ajzen (1991), Najafi et al. (2017), Daellenbach et al. (2018), Tan et al. (2020), and Ng (2021). Attitude was measured by asking respondents to rate three pairs of adjectives: ineffective-effective, useless-useful, harmful-beneficial. Three dimensions of subjective norm were measured: family or friends; people who are important to the respondent, and social pressure. Three items were used to measure perceived behavioral control: confident to do, up to the respondent, and easy to do. Intention was measured using three items: expect to do, plan to do, and will do. The measurement items of risk perception were adopted from Brewer et al. (2007), Paul and Bhuiyan (2010), and Miceli et al. (2008). Disaster preparedness behavior was measured by asking whether respondents prepared a first-aid kit and made an emergency plan before the arrival of imminent typhoons. Previous studies commonly considered these two items as the principal constituents of the operationalization of personal preparedness (Paul and Bhuiyan 2010; Kohn et al. 2012; Lam et al. 2017). Five items of demographic variables (that is, gender, age, education, income, and housing type) of 


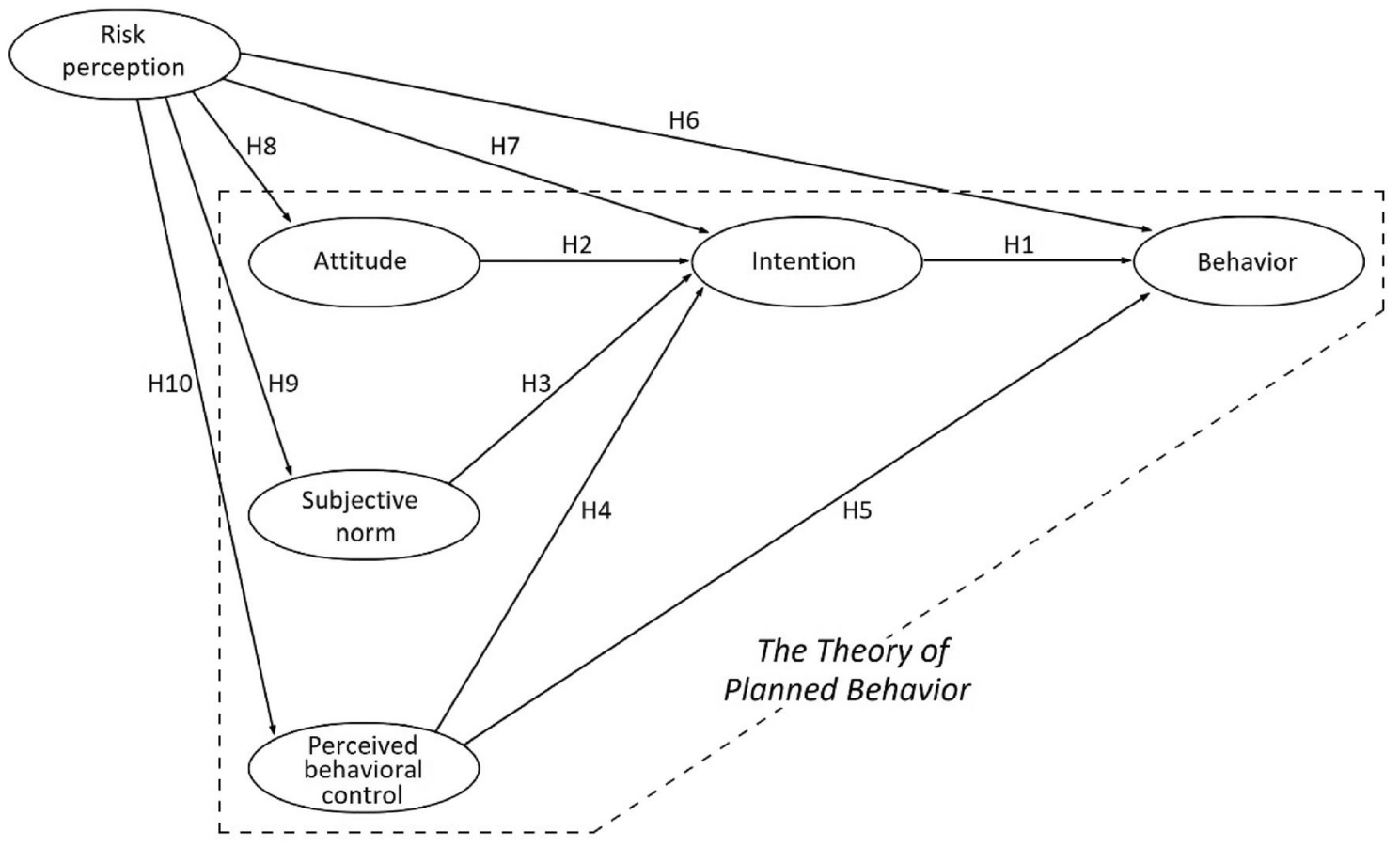

Fig. 1 Conceptual framework used in this study

respondents were asked to obtain their background information.

\subsection{Data Collection}

The research was based on face-to-face interviews conducted on the streets in Kwun Tong. Potential streets, located within a distance of two blocks to the coastline and highly affected by strong winds and heavy rainstorms during typhoons, were first identified from the map, then their suitability for conducting the interview was checked in the field.

There were two reasons for conducting the survey in Kwun Tong. First, Kwun Tong is a typhoon-prone district in Hong Kong. Kwun Tong has high exposure to the impacts of typhoons because of its location and aspects. It also experiences multiple impacts caused by typhoons, including storm surges and landslides because of the local topography and geology (Johnson et al. 2016). Therefore, Kwun Tong residents are generally more exposed to hazards than residents of other districts in Hong Kong. Second, Kwun Tong residents may represent a typhoon vulnerable community, as Kwun Tong is the poorest district in Hong Kong. Its median monthly household income is HK $\$ 15,960$, significantly lower than the median of Hong Kong as a whole (that is, HK\$20,500) (Census and Statistics Department 2011). Kwun Tong also has the highest population density $\left(57,530\right.$ persons per $\left.\mathrm{km}^{2}\right)$ and the largest number of households $(227,168)$ among all
Hong Kong districts (Census and Statistics Department 2016).

To approach suitable respondents for this study, a street intercept survey was believed to be more effective than conventional methods of population survey in Hong Kong because of three reasons: (1) Hong Kong's urban fabric is dominated by high-rise buildings guarded by security checkpoints that deny unsolicited visits (Lo et al. 2017); (2) respondents generally feel more comfortable with interviews in public areas than in the household units (Lo and Jim 2012); and (3) the interviewers can select and check suitable samples before engaging in the interview.

Pedestrians who were visually impaired or illiterate were not invited. Appropriate pedestrians who were Kwun Tong residents above the legal age of 18 and were capable of communication were invited to attend face-to-face interviews. After gaining the consent of suitable respondents, the interviewer engaged with them to complete the questionnaire. Each interview took approximately 15-20 minutes to complete.

To enhance the variability of samples, interviews were conducted on both weekdays and weekends. Furthermore, only one individual was selected from a group of pedestrians. This street survey naturally excluded those people who did not appear on the street for various reasons, such as mobility problems and family roles. However, this did not create a sampling bias because less mobile people are usually less exposed to typhoons. 
Table 1 Constructs and instrument items used in this study

\begin{tabular}{|c|c|c|c|}
\hline Construct & Item & Description & Reference \\
\hline \multirow[t]{3}{*}{ Attitude } & Att1 & $\begin{array}{l}\text { My attitude toward making preparation for typhoon is: } \\
\text { ineffective - effective }\end{array}$ & \multirow[t]{12}{*}{$\begin{array}{l}\text { Ajzen (1991), Najafi et al. (2017), Daellenbach } \\
\text { et al. (2018), Tan et al. (2020) }\end{array}$} \\
\hline & Att2 & $\begin{array}{l}\text { My attitude toward making preparation for typhoon is: useless } \\
\text { - useful }\end{array}$ & \\
\hline & Att3 & $\begin{array}{l}\text { My attitude toward making preparation for typhoon is: harmful } \\
\text { - beneficial }\end{array}$ & \\
\hline \multirow[t]{3}{*}{ Subjective norm } & SN1 & $\begin{array}{l}\text { My family or friends think that I should make preparation for } \\
\text { typhoon. }\end{array}$ & \\
\hline & SN2 & $\begin{array}{l}\text { In regard to making preparation for a typhoon, doing what } \\
\text { people think I should do is important. }\end{array}$ & \\
\hline & SN3 & I feel under social pressure to make preparation for a typhoon. & \\
\hline \multirow{3}{*}{$\begin{array}{l}\text { Perceived } \\
\text { behavioral } \\
\text { control }\end{array}$} & PBC1 & $\begin{array}{l}\text { I am confident that I could make preparation for a typhoon if I } \\
\text { wanted to. }\end{array}$ & \\
\hline & $\mathrm{PBC} 2$ & $\begin{array}{l}\text { Whether I make preparation for a typhoon is entirely dependent } \\
\text { on me. }\end{array}$ & \\
\hline & PBC3 & Making preparation for a typhoon is an easy thing for me. & \\
\hline \multirow[t]{3}{*}{ Intention } & Int1 & I expect to make preparation for a typhoon. & \\
\hline & Int2 & I plan to make preparation for a typhoon. & \\
\hline & Int3 & I will make preparation for a typhoon. & \\
\hline \multirow[t]{3}{*}{ Risk perception } & Risk1 & $\begin{array}{l}\text { I feel that a typhoon has a high chance of becoming a serious } \\
\text { natural hazard-related disaster. }\end{array}$ & \multirow[t]{3}{*}{$\begin{array}{l}\text { Brewer et al. (2007), Paul and Bhuiyan (2010), } \\
\text { Miceli et al. (2008) }\end{array}$} \\
\hline & Risk2 & $\begin{array}{l}\text { I am worried that typhoons are dangerous or catastrophic to } \\
\text { me. }\end{array}$ & \\
\hline & Risk3 & Lower typhoon signals cause no harm to me. & \\
\hline \multirow{2}{*}{$\begin{array}{l}\text { Disaster } \\
\text { preparedness } \\
\text { behavior }\end{array}$} & Prep1 & $\begin{array}{l}\text { Before the coming of a typhoon, I will prepare a first-aid kit for } \\
\text { an emergency. }\end{array}$ & \multirow[t]{2}{*}{$\begin{array}{l}\text { Paul and Bhuiyan (2010), Kohn et al. (2012), } \\
\text { Lam et al. (2017) }\end{array}$} \\
\hline & Prep2 & $\begin{array}{l}\text { Before the coming of a typhoon, I will prepare a household } \\
\text { emergency plan. }\end{array}$ & \\
\hline
\end{tabular}

A total of 300 participants were successfully interviewed. The sample size was comparable to many social surveys in Hong Kong (for example, Wong and Yan 2002) and hazard studies in foreign countries (for example, Shapira et al. 2018).

\subsection{Statistical Analysis}

All questionnaire data were checked for completeness and unresponsive results were removed. Descriptive statistics were used to categorize the socio-demographic characteristics of respondents.

The normality of numerical data was checked and skewed data were log-transformed. Multivariate outliers were identified by calculating the Mahalanobis Distance $(p<0.01)$. Eventually, a total of 286 cases were secured for statistical analysis. The sample size was considered effective for structural equation modeling (Kline 2010). The reliability of the data was tested using Cronbach's alpha. The common method bias of the data was evaluated by the Common Latent Factor method. The above analyses were performed using IBM SPSS Statistics 26.0.

The structural equation modeling was performed to evaluate the theoretical model (that is, the extended theory of planned behavior in this study) based on its consistency with actual data. It allows the examination of causal relations among multiple variables of different levels in a single analysis (Kline 2010). The procedure of structural equation modeling consists of two steps: (1) confirmatory factor analysis assesses the validity of the measurement model by testing the relationships between latent variables and the corresponding items; and (2) path analysis tests the structural model by determining the correlations between latent variables. Based on the results of path analysis, the indirect effects of risk perception on intention and disaster preparedness behavior (that is, the mediations via the constructs of the theory of planned behavior) were assessed using 95\% confidence intervals from 2000 bootstrap samples. The structural equation modeling was performed using IBM SPSS AMOS 26. 


\section{Results}

This section first provides a summary of descriptive statistics. After presenting the results of statistical analysis, the effects of risk perception, attitude, social norm, and perceived behavior control on intention of preparedness and disaster preparedness behavior are elaborated.

\subsection{Descriptive Statistics}

The socio-demographic characteristics of the respondents are outlined in Table 2. The numbers of male (49\%) and female (51\%) respondents were almost equal. Of the respondents, 57\% were youth between the ages of 18-35. The seniors $(3.5 \%)$ were very few. In terms of education, $63.3 \%$ had received a qualification from a university or college. More than two-thirds of the respondents (68.5\%) reported a gross monthly household income in the range of HK $\$ 5000$ to $\$ 39,999 ; 3.5 \%$ and $28 \%$ of the respondents monthly earned $<$ HK\$4999 and > HK\$40,000, respectively. Over half of the respondents $(59.1 \%)$ lived in public housing, and the rest lived in either private housing $(30.8 \%)$ or other types of housing $(10.1 \%)$.

The survey reported high levels of attitude (mean $=3.78$ \pm 0.646 , out of 5 marks), subjective norm (mean $=3.48 \pm$ 0.694 , out of 5 marks), perceived behavioral control (mean $=3.60 \pm 0.590$, out of 5 marks), risk perception (mean = $3.73 \pm 0.637$, out of 5 marks), and intention of preparedness $($ mean $=3.54 \pm 0.692$, out of 5 marks). However, the level of disaster preparedness behavior (mean $=2.59 \pm 0.869$, out of 5 marks) was comparatively low (Table 3). Relatively low levels of preparedness were also reported by a few local studies, for example, Chan et al. (2016) reported that $49.4 \%$ of the respondents had a first-aid kit, and $57.4 \%$ prepared non-perishable food and drinking water; Fung and Loke (2010) reported that $60.6 \%$ of the respondents kept a first-aid kit at home.

\subsection{Testing the Extended Theory of Planned Behavior}

After items SN3 and Risk3 had been deleted, all constructs achieved satisfactory reliability as the Cronbach's $\alpha$ values were higher than the accepted value of 0.7 . The measurement model was assessed by confirmatory factor analysis and the results are also included in Table 3. The construct validity of all constructs was acceptable as the values of loading were higher than the accepted value of 0.6. The composite reliability of all constructs was excellent as the values of construct reliability were higher than the accepted value of 0.6. Discriminant validity was achieved as the values of average variances extracted were higher than the accepted value of 0.50 , and all the correlations between constructs were lower than the square roots of the values of average variances extracted.

Table 2 Socio-demographic characteristics of the respondents (number $=286)$ in this study

\begin{tabular}{|c|c|c|c|}
\hline Characteristic & Category & Number & Percentage $(\%)$ \\
\hline \multirow[t]{2}{*}{ Sex } & 1. Male & 140 & 49.0 \\
\hline & 2. Female & 146 & 51.0 \\
\hline \multirow[t]{6}{*}{ Age } & 1. $18-24$ & 91 & 31.8 \\
\hline & 2. $25-34$ & 72 & 25.2 \\
\hline & 3. $35-44$ & 50 & 17.5 \\
\hline & 4. $45-54$ & 37 & 12.9 \\
\hline & 5. $55-64$ & 26 & 9.1 \\
\hline & 6. $>65$ & 10 & 3.5 \\
\hline \multirow[t]{3}{*}{ Education level } & 1. Primary or below & 11 & 3.8 \\
\hline & 2. Secondary & 94 & 32.9 \\
\hline & 3. Tertiary or above & 181 & 63.3 \\
\hline \multirow[t]{3}{*}{ Household income (monthly) } & 1. $<\mathrm{HK} \$ 4,000$ & 10 & 3.5 \\
\hline & 2. HK\$4,000-HK\$39,999 & 196 & 68.5 \\
\hline & 3. $>\mathrm{HK} \$ 40,000$ & 80 & 28.0 \\
\hline \multirow[t]{3}{*}{ Housing type } & 1. Public estate & 169 & 59.1 \\
\hline & 2. Private estate & 88 & 30.8 \\
\hline & 3. Others (for example, village house) & 29 & 10.1 \\
\hline
\end{tabular}




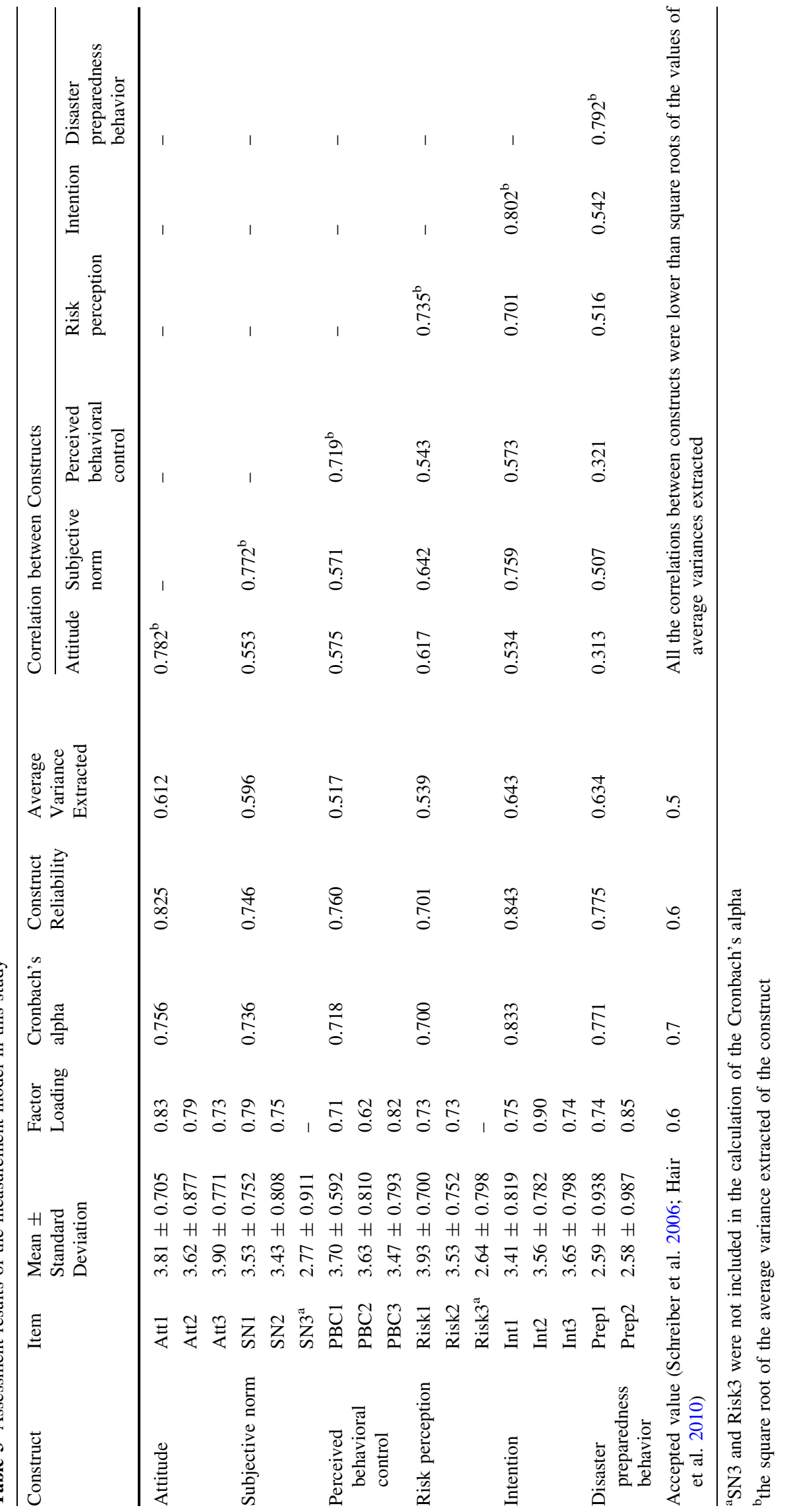


The confirmatory factor analysis generated various indices of fit to reflect the fit between the measurement model and the data set. Important indices of fit are stated as follows: Chi-square to degree of freedom $\left(\chi^{2} / \mathrm{df}\right)=1.87$, comparative fit index $(\mathrm{CFI})=0.965$, Tucker-Lewis index $(\mathrm{TLI})=0.949$, goodness of fit index $(\mathrm{GFI})=0.940$, normed fit index $(\mathrm{NFI})=0.929$, incremental fit index $(\mathrm{IFI})=0.965$, and root mean square error of approximation (RMSEA) = 0.055 . The compliance of indices of fit with recommended values indicated a good fit of the measurement model (Schreiber et al. 2006; Hair et al. 2010).

The same set of indices of fit was generated for the structural model. The results show that the structural model was a good fit, with $\chi^{2} / \mathrm{df}=2.351, \mathrm{CFI}=0.939$, TLI $=$ $0.920, \mathrm{GFI}=0.918, \mathrm{NFI}=0.900, \mathrm{IFI}=0.940$, and RMSEA $=0.069$. The structural model was a good fit because all indices of fit complied with recommended values.

The path analysis evaluated causal relations among the constructs of the structural model (Fig. 2). The correlation between two variables was indicated by the standardized path coefficient. Critical ratio (CR) was calculated to indicate the significance of the path, where significance at 0.05 level if critical ratio $>1.96$, and significance at 0.01 level if critical ratio is $>2.576$. Hypotheses were tested by evaluating the significances of path coefficients. Therefore, hypotheses 3, 8, 9 and 10 were accepted at the significance level of 0.01 , and hypotheses 1,6 , and 7 were accepted at the significance level of 0.05 . Hypotheses 2,4 , and 5 were rejected (Table 4). The $\mathrm{r}^{2}$ values were 0.335 and 0.714 for the constructs of behavior and intention, indicating that the structural model explained $33.5 \%$ and $71.4 \%$ of variances in these two variables, respectively.

\subsection{The Theory of Planned Behavior and Disaster Preparedness Behavior}

The results of structural equation modeling indicated that intention was a significant predictor of behavior $(r=0.343$, $\mathrm{CR}=2.485, p<0.05)$. Therefore, $\mathrm{H} 1$ was accepted. Significant correlations between intention and behavior were reported by previous studies of disaster preparedness behavior (for example, Tan et al. 2020). The level of intention (mean $=3.54 \pm 0.80$ ) was higher than that of behavior (mean $=2.59 \pm 0.96$ ), implying that not all individuals would carry out their intention to perform the behavior (that is, intention-behavior gap). Martins et al. (2019) indicated that situational facilitators and impediments affected the execution of the decision for disaster preparedness.

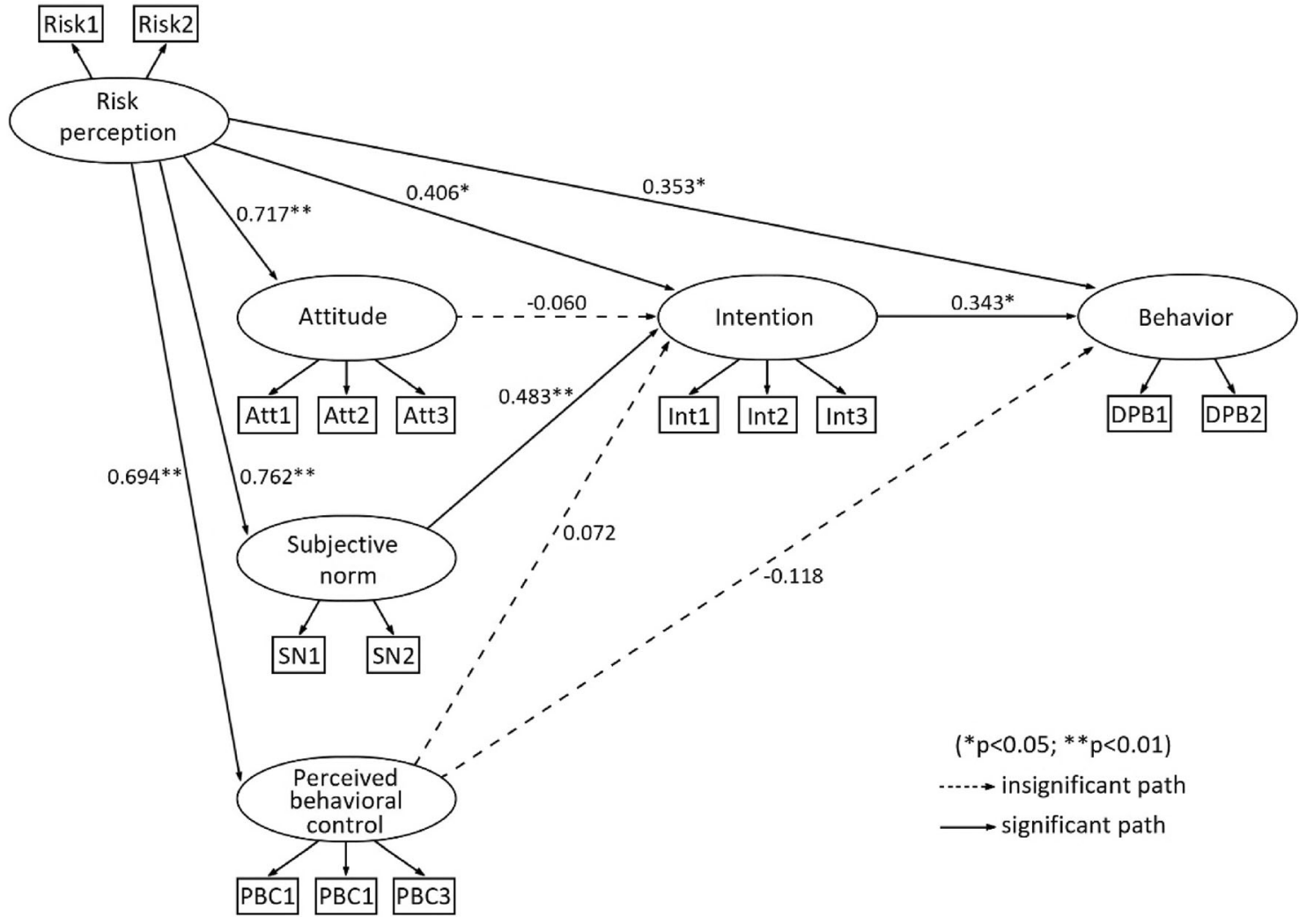

Fig. 2 Structural paths and path coefficients of the structural equation modeling in this study 
Table 4 Verification of hypotheses examined in this study

\begin{tabular}{|c|c|c|c|c|c|}
\hline Hypothesis (Relation) & Estimate & $\begin{array}{l}\text { Standard } \\
\text { Error }\end{array}$ & $\begin{array}{l}\text { Standardized Path } \\
\text { Coefficient }\end{array}$ & $\begin{array}{l}\text { Critical } \\
\text { Ratio }\end{array}$ & Decision \\
\hline H1 (Intention $\rightarrow$ Disaster preparedness behavior) & 3.144 & 1.265 & 0.343 & $2.485^{*}$ & Accepted \\
\hline $\mathrm{H} 2$ (Attitude $\rightarrow$ Intention) & -0.063 & 0.104 & -0.060 & 0.604 & Rejected \\
\hline H3 (Subjective norm $\rightarrow$ Intention) & 0.060 & 0.016 & 0.483 & $3.843 * *$ & Accepted \\
\hline H4 (Perceived behavioral control $\rightarrow$ Intention) & 0.107 & 0.142 & 0.072 & 0.758 & Rejected \\
\hline $\begin{array}{l}\text { H5 (Perceived behavioral control } \rightarrow \text { Disaster preparedness } \\
\text { behavior) }\end{array}$ & -1.619 & 1.578 & -0.118 & 1.037 & Rejected \\
\hline H6 (Risk perception $\rightarrow$ Disaster preparedness behavior) & 0.481 & 0.243 & 0.353 & $1.980^{*}$ & Accepted \\
\hline H7 (Risk perception $\rightarrow$ Intention) & 0.060 & 0.031 & 0.406 & $1.972^{*}$ & Accepted \\
\hline H8 (Risk perception $\rightarrow$ Attitude) & 0.101 & 0.013 & 0.717 & $7.858 * *$ & Accepted \\
\hline H9 (Risk perception $\rightarrow$ Subjective norm) & 0.905 & 0.106 & 0.762 & $8.502 * *$ & Accepted \\
\hline H10 (Risk perception $\rightarrow$ Perceived behavioral control) & 0.069 & 0.010 & 0.694 & $7.056 * *$ & Accepted \\
\hline
\end{tabular}

${ }^{*} p<0.05$ if Critical Ratio $>1.96,{ }^{*} p<0.01$ if Critical Ratio $>2.576$

Although significant associations between attitude and intention were found in various settings and contexts (Kraus 1995), attitude was not significantly correlated with intention $(\mathrm{r}=-0.060, \mathrm{CR}=0.604, p>0.05)$ in this study. Therefore, $\mathrm{H} 2$ was rejected. It is probably because attitude does not well explain behavior under extreme conditions (Turaga et al. 2010). Glasman and Albarracín (2006) indicated that attitude was a more reliable predictor of behavior if it was easy to recall and was stable over time. Since disaster is not a matter of daily life, residents may not have stable attitudes toward disaster preparedness.

Among the three basic constructs of theory of planned behavior, subjective norm was the only significant predictor of intention of preparedness $(\mathrm{r}=0.483, \mathrm{CR}=3.843$, $p<0.01)$. The acceptance of $\mathrm{H} 3$ indicated that society played an important role in a person's decision to take action (for example, Najafi et al. 2017; Tan et al. 2020). When the residents were aware of the expectation of preparedness from family, friends, and society, they were more willing to prepare for typhoons. It is because people interact with others (such as friends and family members) to form a social environment that gives meaning (value, benefit, and so on) to the decision for action (Becker et al. 2012).

$\mathrm{H} 4$ and $\mathrm{H} 5$ were rejected because perceived behavioral control was not significantly correlated with intention $(\mathrm{r}=$ $0.072, \mathrm{CR}=0.758, p>0.05)$ and behavior $(\mathrm{r}=-0.118, \mathrm{CR}$ $=1.037, p>0.05)$, respectively. Similar findings were reported by a few studies of disaster preparedness (for example, Najafi et al. 2017; Tan et al. 2020). Because the impacts of a disaster are often insurmountable and beyond human imagination, people cannot control the outcome even with preparedness. The low outcome expectancy cuts off the associations between perceived behavioral control, intention, and behavior (Artistico et al. 2014). Consequently, people become reluctant to prepare and/or transfer the responsibility of preparedness from themselves to other parties, for instance, the government (Paton 2019). Fung and Loke (2010) reported that nearly half of the surveyed households were confident that the government could manage disastrous situations.

\subsection{Risk Perception and Disaster Preparedness}

Interestingly, significant correlations were found between risk perception and all studied variables in this study. Risk perception was significantly correlated with disaster preparedness behavior $(\mathrm{r}=0.353, \mathrm{CR}=1.980, p<0.05)$ and intention ( $\mathrm{r}=0.406, \mathrm{CR}=1.972, p<0.05)$, respectively. Therefore, both H6 and H7 were accepted. Previous studies reported that risk perception was significantly correlated with disaster preparedness behavior and intention in various hazard contexts and settings, for example, landslides (Xu et al. 2016), floods (Miceli et al. 2008), earthquakes (Becker et al. 2012), and hurricanes (Martins et al. 2019).

Risk perception was also a significant predictor of the three constructs of the theory of planned behavior. Risk perception was correlated with attitude $(\mathrm{r}=0.717, \mathrm{CR}=$ $7.858, p<0.01)$, subjective norm $(\mathrm{r}=0.762, \mathrm{CR}=8.502$, $p<0.01)$, and perceived behavior control $(\mathrm{r}=0.694, \mathrm{CR}=$ $7.056, p<0.01$ ), respectively. Therefore, $\mathrm{H} 8, \mathrm{H} 9$, and $\mathrm{H} 10$ were accepted. These findings generally are consistent with existing studies of attitude (for example, Marti et al. 2017), subjective norm (for example, Najafi et al. 2017; Tan et al. 2020), and perceived behavioral control (for example, LiuLastres et al. 2019).

The above findings confirm that risk perception generates a multitude of effects on a person who decides to 
perform disaster preparedness behavior. Risk perception influences intention of preparedness and disaster preparedness behavior via two types of channels. The first type is the "direct" channels, as indicated by the significant correlations between risk perception, intention, and disaster preparedness behavior. The second type is the "indirect" channels via subjective norm. Table 5 summarizes the important statistics of the indirect effects of risk perception on intention and behavior.

\section{Discussion}

This study has a few theoretical and practical implications. For theoretical implications, this study confirmed the value of adding risk perception to the theory of planned behavior. The extended theory of planned behavior effectively predicted intention of disaster preparedness and disaster preparedness behavior. As the values of $r^{2}$ exceed the threshold of 0.26 , the model is considered substantial (Cohen 1988). Specifically, the extended theory of planned behavior can explain $33.5 \%$ of the variances in behavior, and $71.4 \%$ of the variances in intention, respectively, performing better than the original theory of planned behavior. A meta-analysis of 206 independent studies reported that, on average, the theory of planned behavior explained $19.3 \%$ of the variances in behavior and $44.3 \%$ of the variances in intention, respectively (McEachan et al. 2011). Second, this study presented a roadmap to show how risk perception and behavioral variables affected intention of disaster preparedness and disaster preparedness behavior. Although risk perception is believed to generate a multitude of effects on disaster preparedness behavior, the process of how risk perception affects disaster preparedness behavior has not yet been clarified by the existing literature. Whereas Miceli et al. (2008) indicated that risk perception encompassed both cognitive and affective impacts on a person's decision on preparedness, Loewenstein et al. (2001) indicated that risk perception exerted both direct and indirect influences on behavior. This study demonstrated that, apart from the direct effect on intention of preparedness and disaster preparedness behavior, the indirect effects of risk perception was exerted via subjective norm.

This study also offers practical insights that enhance personal and household preparedness toward typhoons. Due to the importance of risk perception for disaster preparedness, educational and promotional programs are always necessary to enhance risk perception and awareness in society (Chan et al. 2016). Equally important is to identify and understand the factors that distort risk perception, and hence lead to inappropriate decisions for disaster preparedness behavior. Only when people realize the risks associated with typhoons, they become motivated to prepare accordingly (Lazo et al. 2015). Significantly, subjective norm was the only construct of the theory of planned behavior that had a significant correlation with intention of preparedness, highlighting the importance of social influence on a person's disaster preparedness. While conventional initiatives to promote preparedness target the individual's decision, they often neglect the social context of that decision (Becker et al. 2012). Because people are more likely to adopt preparedness measures if they observe or believe that others have prepared, it is important to cultivate the preparedness culture in local communities.

This study has a few noted limitations. The first limitation is the reporting bias associated with the self-reported questionnaire. What the respondents had reported might not be accurate and objective measures of what they thought and how they behaved. However, validating the opinions collected from the respondents is impossible. Second, although this study had developed the survey protocol that aimed at a good control of data quality, younger and well-educated respondents were over-represented, which might have biased the results. Third, this study had only interviewed respondents from one district in Hong Kong, so the samples did not represent the general population of Hong Kong. Hence, the findings should be

Table 5 Indirect effects of risk perception on intention and disaster preparedness behavior

\begin{tabular}{lll}
\hline Path & $\begin{array}{l}\text { Risk Perception } \rightarrow \\
\text { Subjective Norm } \rightarrow \\
\text { Intention }\end{array}$ & $\begin{array}{l}\text { Risk Perception } \rightarrow \\
\text { Subjective Norm } \rightarrow \\
\text { Intention } \rightarrow \\
\text { Disaster Preparedness Behavior }\end{array}$ \\
\hline Standard indirect effect & 0.389 & 0.257 \\
Standard error of 2,000 bootstrap samples & 0.097 & 0.099 \\
$95 \%$ C.I. Lower Bound & 0.233 & 0.077 \\
$95 \%$ C.I. Upper Bound & 0.620 & 0.468 \\
Type of mediation & Partial & Partial \\
\hline
\end{tabular}


interpreted with caution. Fourth, relations identified by the structural equation modeling were limited to statistical inferences and could not be recognized as causation. Nevertheless, these findings cast light on developing research questions and hypotheses that inform future studies. Qualitative methods, such as in-depth interviews, are useful to understand the causal relations between disaster preparedness behavior and its predictors. Despite the above limitations, this study was able to integrate risk perception and the theory of planned behavior into a united model that can be used to predict the disaster preparedness behavior of typhoon vulnerable people in Hong Kong.

\section{Conclusion}

Facing the challenges brought by typhoons, a robust body of research has explored various options for reducing the risks of typhoon impacts. Social scientists emphasize the importance of personal disaster preparedness for reducing hazard vulnerability in the process of disaster management. This study adopted an extended theory of planned behavior to predict the disaster preparedness behavior of typhoonvulnerable people in Hong Kong by using the data acquired from an intercept survey. Confirmatory factor analysis affirmed the validity of the model and the final structural equation model adequately fits the data. The results indicated that risk perception directly affected intention of preparedness and disaster preparedness behavior, while generating indirect effects via subjective norm. Although risk perception changed attitude and perceived behavioral control, the changes had no significant effects on intention of preparedness and disaster preparedness behavior. This study demonstrated the value of extending the original theory of planned behavior by adding risk perception as the new variable for predicting personal typhoon preparedness. Educational and promotional programs are necessary to enhance risk perception and cultivate a preparedness culture in society.

Acknowledgements The author is grateful to Ms. Joni Fung Mei Wong for organizing the questionnaire survey. The author is also grateful to Ms. Joey Cheuk Yee Chan for carrying out the field interview. Thanks are given to Mr. Andrew Yan To Ng for polishing and editing the manuscript.

Open Access This article is licensed under a Creative Commons Attribution 4.0 International License, which permits use, sharing, adaptation, distribution and reproduction in any medium or format, as long as you give appropriate credit to the original author(s) and the source, provide a link to the Creative Commons licence, and indicate if changes were made. The images or other third party material in this article are included in the article's Creative Commons licence, unless indicated otherwise in a credit line to the material. If material is not included in the article's Creative Commons licence and your intended use is not permitted by statutory regulation or exceeds the permitted use, you will need to obtain permission directly from the copyright holder. To view a copy of this licence, visit http://creativecommons. org/licenses/by/4.0/.

\section{References}

Ajzen, I. 1991. The theory of planned behavior. Organizational Behavior and Human Decision Process 50(2): 179-211.

Ajzen, I. 2002. Perceived behavioral control, self-efficacy, locus of control, and the theory of planned behavior. Journal of Applied Social Psychology 32(4): 665-683.

Ajzen, I. 2011. The theory of planned behavior: Reactions and reflections. Psychology \& Health 26(9): 1113-1127.

Armitage, C.J., and M. Conner. 2001. Efficacy of the theory of planned behaviour: A meta-analytic review. British Journal of Social Psychology 40(4): 471-499.

Artistico, D., L. Oliver, S. Dowd, A. Rothenberg, and M. Khalil. 2014. The predictive role of self-efficacy, outcome expectancies, past behavior and attitudes on condom use in a sample of female college students. Journal of European Psychology Students 5(3): 100-107.

Becker, J.S., D. Paton, D.M. Johnston, and K.R. Ronan. 2012. A model of household preparedness for earthquakes: How individuals make meaning of earthquake information and how this influences preparedness. Natural Hazards 64(1): 107-137.

Bhanumurthy, V., G.J. Shankar, K.R.M. Rao, and P.V. Nagamani. 2015. Defining a framework for integration of geospatial technologies for emergency management. Geocarto International 30(9): 963-983.

Bourque, L.B., R. Regan, M.M. Kelley, M.M. Wood, M. Kanp, and D.S. Mileti. 2012. An examination of the effect of perceived risk on preparedness behavior. Environment and Behavior 45(5): 615-649.

Brewer, N., G. Chapman, F.X. Gibbons, M. Gerrard, K. McCaul, and N. Weinstein. 2007. Meta-analysis of the relationship between risk perception and health behavior: The example of vaccination. Health Psychology 26(2): 136-145.

Census and Statistics Department. 2011. 2011 population census: Summary results. Hong Kong: Hong Kong special administrative region government. https://www.statistics.gov.hk/pub/ B11200552011XXXXB0100.pdf. Accessed 10 Sept 2021.

Census and Statistics Department. 2016. 2016 population by-census: Main results. Hong Kong: Hong Kong Special Administrative Region Government. https://www.bycensus2016.gov.hk/data/ 16bc-main-results.pdf. Accessed 10 Sept 2021.

Chan, E., J. Yue, P. Lee, and S. Wang. 2016. Socio-demographic predictors for urban community disaster health risk perception and household based preparedness in a Chinese urban city. PLoS Currents Disasters. https://doi.org/10.1371/currents.dis. 287fb7fee6f9f4521af441a236c2d519.

Cohen, J. 1988. Statistical power analysis for the behavioral sciences, 2nd edn. New York: Lawrence Erlbaum Associates.

Cooper, T., and A. Faseruk. 2011. Strategic risk, risk perception and risk behaviour: Meta-analysis. Journal of Financial Management and Analysis 24(2): 20-29.

Daellenbach, K., J. Parkinson, and J. Krisjanous. 2018. Just how prepared are you? An application of marketing segmentation and theory of planned behavior for disaster preparation. Journal of Nonprofit \& Public Sector Marketing 30(4): 413-443.

Dasgupta, R., M. Basu, P. Kumar, B.A. Johnson, B.K. Mitra, R. Avtar, and R. Shaw. 2020. A rapid indicator-based assessment of foreign resident preparedness in Japan during Typhoon Hagibis. International Journal of Disaster Risk Reduction 51: Article 101849. 
Doocy, S., A. Dick, A. Daniels, and T.D. Kirsch. 2013. The human impact of tropical cyclones: A historical review of events 1980-2009 and systematic literature review. PLOS Currents Disasters. 2664354a5571512063ed29d25ffbce74.

Eagly, A.H., and S. Chaiken. 2007. The advantages of an inclusive definition of attitude. Social Cognition 25(5): 582-602.

Fok, L., and L.T.O. Cheung. 2012. Evaluating the impact reduction strategies for the tropical cyclone hazard in Hong Kong. Asian Geographer 29(2): 121-129.

Fung, O.W.M., and A.Y. Loke. 2010. Disaster preparedness of families with young children in Hong Kong. Scandinavian Journal of Public Health 38(8): 880-888.

Glasman, L.R., and D. Albarracín. 2006. Forming attitudes that predict future behavior: A meta-analysis of the attitude-behavior relation. Psychological Bulletin 132(5): 778-822.

Hair, J., W. Black, J. Babin, and R. Anderson. 2010. Multivariate data analysis, 7th edn. Upper Saddle River: Prentice-Hall.

Hong Kong Observatory. 2020. Tropical cyclones in 2019. Hong Kong: Hong Kong Observatory. https://www.hko.gov.hk/en/ publica/tc/files/TC2019.pdf. Accessed 10 Sept 2021.

Jang, L.J., J.J. Wang, D. Paton, and N.Y. Tsai. 2016. Cross-cultural comparisons between the earthquake preparedness models of Taiwan and New Zealand. Disasters 40(2): 327-345.

Johnson, K., Y. Depietri, and M. Breil. 2016. Multi-hazard risk assessment of two Hong Kong districts. International Journal of Disaster Risk Reduction 19: 311-323.

Khalil, T., K. Atieh, A.U. Mohammad, and F. Bagdadlian. 2014. Examining the social and technical factors influencing school teachers knowledge sharing intentions in a teachers online professional community. Electronic Journal of Knowledge Management 12(3): 157-165.

Kline, R.B. 2010. Principles and practice of structural equation modeling. New York: Guilford.

Kohn, S., J.L. Eaton, S. Feroz, A.A. Bainbridge, J. Hoolachan, and D.J. Barnett. 2012. Personal disaster preparedness: An integrated review of the literature. Disaster Medicine and Public Health Preparedness 6(3): 217-231.

Kraus, S.J. 1995. Attitudes and the prediction of behavior: A metaanalysis of the empirical literature. Personality and Social Psychology Bulletin 21(1): 58-75.

Kuran, C.H.A., C. Morsut, B.I. Kruke, M. Krüger, L. Segnestam, K. Orru, T.O. Nævestad, M. Airola, et al. 2020. Vulnerability and vulnerable groups from an intersectionality perspective. International Journal of Disaster Risk Reduction 50: Article 101826.

Lam, K.M., and P. To. 2009. Statistical analysis of extreme wind speeds in Hong Kong and Macau. HKIE Transactions 16(1): 21-28.

Lam, R.P.K., L.P. Leung, S. Balsari, K.-H. Hsiao, E. Newnham, K. Patrick, P. Pham, and J. Leaning. 2017. Urban disaster preparedness of Hong Kong residents: A territory-wide survey. International Journal of Disaster Risk Reduction 23: 62-69.

Lazo, J.K., A. Bostrom, R.E. Morss, J.L. Demuth, and H. Lazrus. 2015. Factors affecting hurricane evacuation intentions. Risk Analysis 35(10): 1837-1857.

Liu-Lastres, B., A. Schroeder, and L. Pennington-Gray. 2019. Cruise line customers' responses to risk and crisis communication messages: An application of the risk perception attitude framework. Journal of Travel Research 58(5): 849-865.

Lo, A.Y., and C.Y. Jim. 2012. Citizen attitude and expectation towards greenspace provision in compact urban milieu. Land Use Policy 29(3): 577-586.

Lo, A.Y., J.A. Byrneb, and C.Y. Jim. 2017. How climate change perception is reshaping attitudes towards the functional benefits of urban trees and green space: Lessons from Hong Kong. Urban Forestry \& Urban Greening 23: 74-83.
Loewenstein, G.F., E.U. Weber, C.K. Hse, and N. Welch. 2001. Risk as feelings. Psychological Bulletin 127(2): 267-286.

Loke, A.Y., C.K.Y. Lai, and O.W.M. Fung. 2010. At-home disaster preparedness of elderly people in Hong Kong. Geriatrics \& Gerontology International 12(3): 524-531.

Manstead, A.S.R., and S.A.M. van Eekelen. 1998. Distinguishing between perceived behavioral control and self-efficacy in the domain of academic intentions and behaviors. Journal of Applied Social Psychology 28(15): 1375-1392.

Marti, M., M. Stauffacher, J. Matthes, and S. Wiemer. 2017. Communicating earthquake preparedness: The influence of induced mood, perceived risk, and gain or loss frames on homeowners' attitudes toward general precautionary measures for earthquakes. Risk Analysis 38(4): 710-723.

Martins, V.N., J. Nigg, H.M. Louis-Charles, and J.M. Kendra. 2019. Household preparedness in an imminent disaster threat scenario: The case of superstorm Sandy in New York City. International Journal of Disaster Risk Reduction 34: 316-325.

McEachan, R.R.C., M. Conner, N.J. Taylor, and R.J. Lawton. 2011. Prospective prediction of health-related behaviours with the theory of planned behaviour: A meta-analysis. Health Psychology Review 5(2): 97-144.

McIvor, D., and D. Paton. 2007. Preparing for natural hazards: Normative and attitudinal influences. Disaster Prevention and Management 16(1): 79-88.

Miceli, R., I. Sotgiu, and M. Settanni. 2008. Disaster preparedness and perception of flood risk: A study in an alpine valley in Italy. Journal of Environmental Psychology 28(2): 164-173.

Najafi, M., A. Ardalan, A. Akbarisari, A.A. Noorbala, and H. Elmi. 2017. The theory of planned behavior and disaster preparedness. PLOS Currents Disasters 9. http://currents.plos.org/disasters/ index.html\%3Fp=31955.html. Accessed 31 Jan 2022.

Najafi, M., H. Khankeh, H. Elmi, and N. Pourvakhshoori. 2018. Behavioral, normative and control beliefs about earthquake preparedness: A deductive content analysis study. PLOS Currents Disasters 10. http://currents.plos.org/disasters/index.html\% $3 \mathrm{Fp}=32519 . \mathrm{html}$. Accessed 31 Jan 2022.

$\mathrm{Ng}$, S.L. 2021. Would you speak softly in public? An investigation of pro-environmental behavior of outbound tourists in Hong Kong. Current Issues in Tourism 24(22): 3239-3255.

Paton, D. 2019. Disaster risk reduction: Psychological perspectives on preparedness. Australian Journal of Psychology 71: 327-341.

Paul, B., and R. Bhuiyan. 2010. Urban earthquake hazard: Perceived seismic risk and preparedness in Dhaka City Bangladesh. Disasters 34(2): 337-359.

Rimal, R.N., and K. Real. 2003. Perceived risk and efficacy beliefs as motivators of change: Use of the risk perception attitude (RPA) framework to understand health behaviors. Human Communication Research 29(3): 370-399.

Schreiber, J.B., A. Nora, F.K. Stage, E.A. Barlow, and J. King. 2006. Reporting structural equation modeling and confirmatory factor analysis results: A review. The Journal of Educational Research 99(6): 323-338.

Shapira, S., L. Aharonson-Daniel, and Y. Bar-Dayan. 2018. Anticipated behavioral response patterns to an earthquake: The role of personal and household characteristics, risk perception, previous experience and preparedness. International Journal of Disaster Risk Reduction 31: 1-8.

Sheeran, P. 2002. Intention-behavior relations: A conceptual and empirical review. European Review of Social Psychology 12(1): $1-36$.

Shreve, C., C. Begg, M. Fordham, and A. Müller. 2016. Operationalizing risk perception and preparedness behavior research for a multi-hazard context. Environmental Hazards 15(3): 227-245.

Sommestad, T., H. Karlzén, and J. Hallberg. 2015. The sufficiency of the theory of planned behavior for explaining information 
security policy compliance. Information \& Computer Security 23(2): 200-217.

Sundermann, L., O. Schelske, and P. Hausmann. 2013. Mind the risk: A global ranking of cities under threat from natural disasters. Zurich: Swiss Re. https://www.swissre.com/Library/mind-therisk-a-global-ranking-of-cities-under-threat-from-natural-disas ters.html. Accessed 10 Sept 2021.

Tan, K.-L., J.K.-M. Sia, and K.H.D. Tang. 2020. Examining students' behavior towards campus security preparedness exercise: The role of perceived risk within the theory of planned behavior. Current Psychology. https://doi.org/10.1007/s12144-020-009516.

Turaga, R.M.R., R.B. Howarth, and M.E. Borsuk. 2010. Proenvironmental behavior: Rational choice meets moral motivation. Annals of the New York Academy of Sciences 1185(1): 211-224.
UNISDR (United Nations International Strategy for Disaster Reduction). 2015. Sendai framework for disaster risk reduction 20152030. Geneva: United Nations Office for Disaster Risk Reduction. https://www.undrr.org/publication/sendai-framework-disas ter-risk-reduction-2015-2030. Accessed 10 Sept 2021.

Webster, P.J., G.J. Holland, J.A. Curry, and H.R. Chang. 2005. Changes in tropical cyclone number and intensity in a warming environment. Science 309(5742): 1844-1846.

Wong, T., and Y. Yan. 2002. Perceptions of severe weather warnings in Hong Kong. Meteorological Applications 9(3): 377-382.

Xu, D., L. Peng, C. Su, S. Liu, X. Wang, and T. Chen. 2016. Influences of mass monitoring and mass prevention systems on peasant households' disaster risk perception in the landslidethreatened Three gorges reservoir area, China. Habitat International 58: 23-33. 